\title{
The Idea of Landing Sites and Its Inheritance through Tactileology
}

\author{
Fuminori Akiba
}

Citation: Akiba, F. The Idea of Landing Sites and Its Inheritance through Tactileology. Philosophies 2021, 6, 66. https://doi.org/10.3390/ philosophies6030066

Academic Editors: Yasuhiro Suzuki and Marcin J. Schroeder

Received: 24 May 2021

Accepted: 3 August 2021

Published: 6 August 2021

Publisher's Note: MDPI stays neutral with regard to jurisdictional claims in published maps and institutional affiliations.

Copyright: (C) 2021 by the author Licensee MDPI, Basel, Switzerland. This article is an open access article distributed under the terms and conditions of the Creative Commons Attribution (CC BY) license (https:// creativecommons.org/licenses/by/ $4.0 /)$.
Graduate School of Informatics, Nagoya University, Nagoya 464-8601, Japan; akibaf@i.nagoya-u.ac.jp

\begin{abstract}
From the perspective of sustainability, empowering people to live positively without being dominated by death is an important issue. One thing we can do in this vein is to expand one's own physical sensation, which is the basis for us to live. From this point of view, Shusaku Arakawa and Madeline Gins' idea of "landing sites" is very important. Landing sites are physical experiences that result from person-environment collaboration. In order to make as many people as possible aware of their physical sensations through landing sites, Arakawa and Gins created artificial environments such as "Site of Reversible Destiny Yoro" where people could gain new physical sensations. They wanted people to build new ethics and move toward social reformation based on their new physical sensations. However, at present, these artificial environments have some problems. It is the time to seriously consider how we can pass on the experience of landing sites to future generations. The aim of this paper is to provide an answer to the question by Yasuhiro Suzuki's scientific research on tactile sense, called tactileology. I first introduce Arakawa and Gin's text about the idea of "landing sites" and make clear its importance. Next, I point out that, now, "landing sites" present certain difficulties. I then confirm that tactileology inherits the idea of "landing sites".
\end{abstract}

Keywords: tactileology; tactile score; landing sites

\section{Introduction}

From the perspective of sustainability, empowering people to live positively without being dominated by death is an important issue. One thing we can do in this vein is to expand one's own physical sensation, which is the basis for us to live. From this point of view, Shusaku Arakawa (1936-2010) and his partner, Madeline Gins (1941-2014), a poet, (hereinafter referred to as Arakawa + Gins) have been highly acclaimed worldwide. Their works attempted to expand the human body and reverse the destiny of mortal human beings, as represented by the "Site of Reversible Destiny Yoro" (1995) or "Reverse Destiny Lofts Mitaka" (2005). People who visit these sites are "stimulated by slopes and uneven roads and floors. They stimulate visitors' vision, sense of balance, the soles of their feet, and the muscles of the lower limbs while activating their minds and bodies. As a result, the power to live positively beyond death is further activated" [1] (p. 126, translation from Japanese into English by the author). In American philosopher Arthur Danto's words, they attempted to change "the limit death imposes upon human life" [2] (p. 267). It was in 2020 that their work once again aroused people's interest, as it was not only the 10-year anniversary of Arakawa's death, it was also the year when the COVID-19 pandemic began to have a major impact on the world. A Japanese online art magazine announced that the Arakawa + Gins office began publishing an online newsletter in response to the coronavirus crisis.

"The spread of the novel coronavirus led to the blockade of cities and disconnection from the outside world. In light of this situation, the Arakawa + Gins Tokyo Office and the Reversible Destiny Foundation have started distributing the newsletter "STAY HOME: Distraction Series" on the web. In the first installment, 
director Nobutaka Yamaoka an-nounced the free release of the documentary film 'Children Who Won't Die, Shusaku Arakawa'”' (2010) [3].

If Arakawa + Gins, who aimed to reverse the human destiny of dying and emphasized bodily activities, were alive, how would they discuss this situation? Their ideas are still needed worldwide, and in their absence, we consider how their ideas may be applied in this new context. The following section is an attempt to realize new "landing sites" based on Yasuhiro Suzuki's research on tactile sense, which he calls "tactileology." I believe that tactileology is an attempt to inherit the idea of Arakawa + Gins.

\section{Landing Sites}

Among the ideas of Arakawa + Gins, one of the most important was "landing sites." Think about walking from the other side of the room to the desk, sitting on a chair, picking up a coffee cup from the desk, and drinking coffee from the cup. These are all landing sites. How can such "landing sites" be defined? The words of Arakawa + Gins, in the text "Architectural Body," confirm their description [4]. Before introducing the text in detail, however, I would like to draw the readers' attention to the following two points.

The first is the stance that this study takes with respect to previous studies. Previous studies have associated the term "landing sites" with theories of phenomenology, autopoiesis, affordances, and so on [5], which are certainly significant. However, this study did not do so for three reasons. First, "Architectural Body" by Arakawa + Gins seems incomplete or inconsistent when researchers attempt to interpret it in a unified way from an established theoretical perspective. For example, if researchers interpret the text phenomenologically based on the seemingly Heideggerian concept of "the World" Arakawa + Gins utilize, their attempt will not succeed because Arakawa + Gins never introduce its essential counterpart, the concept of "the Earth." If researchers attempt to suggest affinity based on the theory of affordance, their attempt will not succeed because Arakawa + Gins introduced the idea of "depth" or "inference," which the affordance theory clearly denies. Second, such inconsistencies and contradictions were the usual methods employed by Arakawa + Gins to prevent readers from identifying their intentions or to attract the attention of people from diverse disciplines, including scientists and philosophers. The same approach was applied to Arakawa's paintings. Although they ostensibly looked like paintings, they did "not work in the way that other paintings" did [6]. Such inconsistencies keep us from moving forward. Third, to associate the text of Arakawa + Gins with various theories and to describe it as esoteric creates the misunderstanding that the "landing sites" they described can only arise from their own work, and as they are both no more, we have no choice but to, ourselves, establish some kind of "landing sites" according to the current situation. As discussed later, when we read the text with the help of a good interpreter, it becomes clear that it is not esoteric.

The second point is that landing sites refer to multiple landings that continue to be realized through the collaboration between the acting person and their environment. "Through landing-site configurations, organism-person-environment takes hold and holds forth" [4] (p. 9). Therefore, even if this quotation from "Architectural Body" men-tions a "landing site," I hope that the readers will understand it in the sense that it is embedded within innumerable landing sites. Just as multiple micro landing sites must progress in parallel through the collaboration between each part of the body and the environments to grab a coffee cup, "[1] anding sites abound within landing sites" [4] (p. 9).

\subsection{Landing Sites Are Procedural}

From here, I would like to concretely confirm the characteristics of landing sites in the words of Arakawa + Gins. First, the landing sites they discussed are procedural. The following passage is a statement that helps us understand it.

"A multiple, complex siting process or procedure would seem to be in effect as or-ganism-person-environment; or posing it more neutrally, the world one finds in place lends itself to being mapped by means of a multiple, complex siting 
process or procedure. Human action depends on an attributing of sites and takes place in large part through sequences of sitings. In determining her surroundings, a person proceeds by registering a "this here" and a "that here" and a "more of this here" and a "more of that there." In fielding her surroundings, she makes use of cues from the environment to assign volume and a host of particulars to world and to body, complying with what comes her way as best she can. Her fielding of her surroundings never ceases, continuing even in sleep. Whatever comes up in the course of this fielding should be considered a landing site" [4] (p. 7).

Nothing difficult was said. If you walk and hit your toe against a stone, you have failed to create landing sites with depth. Conversely, if you walk without hitting anything, you have successfully landed the sites with depth. Thus, when trying to grab a coffee cup at a distance with your hand and fail to, when you hit your foot against the corner of the desk, when you turn a corner and hit a person on the head, or when you turn over and your head falls off your pillow, it is likely that you are failing to land sites. Our daily lives are full of innumerable multiple landing procedures.

\subsection{Three Landing Site Types: Perceptual, Imaging, and Depth}

According to Arakawa + Gins, we use a combination of two landing sites when landing such sites with depth. One is direct perception (perceptual landing site), and the other is indirect perception (imaging landing site).

"Defining features (perceptual landing sites), plus all the imaging that bounces off that which surrounds a person (imaging landing sites), plus guesses and judgments as to how elements of the surroundings are positioned (dimensionalizing landing sites), fab-ricate a world or suffice to map one. Landing sites dissolve into each other, or abut, or overlap, or nest within one another" [4] (p. 8).

Although they do not define a strict boundary between direct and indirect perception, such a combination of direct and indirect perception describes that which we normally utilize. For example, when turning the corner of a building around which we cannot directly see, we will perform the act of turning by relying on what we can directly perceive and the image of the place ahead (e.g., "it will be like this"). As we walk through unfamiliar cities, we are supported by a combination of what we can perceive directly (for example, the perception of the building we see in front of us) and of what we can perceive indirectly (imitated perception of positional relationships obtained from the map). If successful, sequences of landing sites with depth will occur. However, we are not particularly aware that we have landed at such sites, because the landing is usually successful, and we are busy landing on the following sites in quick succession. We are also unaware that we combine two landing sites: perception and image.

If landing sites go through such processes, it seems that there is no need to interpret them esoterically just because they are written poetically. In fact, the following, definitionlike sentence of Arakawa + Gins can be understood to some extent.

"Every landing-site configuration-that is, every instance of the world-involves all three ways of landing as a site. A perceptual landing site lands narrowly as an immediate and direct response to a probable existent, a bit of reporting on what presents itself. An imaging landing site lands widely and in an un-pinpointing way, dancing attendance on the perceptual landing site, responding indirectly and diffusely to whatever the latter leaves unprocessed" [4] (p. 7, italics by the original author).

"A dimensionalizing landing site lands simultaneously narrowly and tightly and widely and diffusely, combining the qualities of a perceptual landing site with those of an imaging one, coupling and coordinating direct responses with indirect ones, the formed with the formless" [4] (p. 8, italics by the original author).

In fact, we are living by creating instances of the world one after another. It is just too obvious to be aware of. 


\subsection{Landing Sites Are Corporeal}

From the above, it can be easily understood that landing sites, especially perceptual landing sites, are closely related to the body, as Arakawa + Gins stated:

"Were there no perceptual landing sites, there could be no organism-person that is a body. Perceptual landing sites serve up the initiating site of all sites, the basically fixed but constantly changing kinesthetic-proprioceptive schema of body that keeps a person always kinesthetically grounded, figured, and configured. Nothing happens without kinesthetic instigation, corporeal proddings. All events have palpably active starts, stops, turnabouts, and kinesthetic repercussions. A mobile and sculpted medium of locatings or events composed of kinesthetic- and proprioceptive-perceptual landing sites animates the show from within and in great measure runs it" [4] (p. 11).

The important concept presented here is that landing sites are certainly called "sites," but they do not mean specific places or specific constructions. They are "sitings" - they are something that persons and the environments collaboratively create each time, so they are only procedural and tentative.

\section{Why Are Landing Sites Important?}

However, such characterizations of landing sites say nothing special, but simply point out the obvious. The following two points are important. First, Arakawa + Gins attempted to transform peoples' bodies and consciousness through landing sites at, for example, "Site of Riversible Destiny Yoro." Second, they believed that landing sites should not be limited to personal experience.

\subsection{Sensational Transformation toward Social Reformation}

Concerning the first point, I introduce Arakawa's remark that appeared in a work by Baba [1]. Arakawa (p. 92) stated in dialog with Baba that people must "find out a whole new sensation created by new actions and movements of the body and then, in order to make the new phenomena and facts found in this way valid in our human world, we need new common sense, morality, ethics" and "we should move on to the institutional reform." [1] (p. 92, translated from Japanese to English by the author).

What this "new sensation" means is not very clear, however, the following statement in Baba (2016) [1] is helpful. Shunkichi Baba (1932-) is a doctor, an emeritus professor (Nagoya City University, otorhinolaryngology), haiku poet, art critic, and former director of Nagoya/Boston Museum of Fine Arts who had a close relationship with Arakawa during his lifetime and recognizes himself as Arakawa's interpreter. In fact, Arakawa repeatedly nominated him as a dialog partner [7].

"These two architectural bodies ["Site of Reversible Density Yoro" and "Reversible Density Lofts Mitaka"] continue to exist as structures that we can experience, and we put our bodies in it. As a result, our bodies are exposed to various stimuli. In addition to the visual stimulus of shapes and colors that deviate from the traditional harmonious framework, the space that continues to shake the sense of balance by making heavy use of slopes and irregularities. It reminds us of the floating feeling of the cage and the amniotic fluid that are the basis of our lives, and expels pessimistic thoughts" [1] (p. 135, translation from Japanese into English by the author).

From such a new sensation, we come to know that "new common sense, morality, ethics" are needed and move on to the "institutional reform." The experimental field of such landing sites is the "Site of Reversible Destiny Yoro," as mentioned earlier.

Such artifacts, however, should not be considered complete constructions, independent of the procedural actions of the visitors. Instead, they should resemble Jackson Pollock's poured paintings and pottery in the hands of the masters, though these are not the examples given by Arakawa + Gins. These artifacts are considered traces of creative 
action and perception in the process that results in the artifacts. Because human actions and perceptions occur in particular environments, traces of actions and perceptions are also the traces of collaborative work with the environment. The clay and potter's wheel for ceramics, as well as the paint and canvas for poured paintings, are the partners of collaboration.

Nevertheless, for ordinary people, looking at Pollock's poured paintings or pottery cannot reproduce or remind them of the actions and perceptions of when it was landed. One cannot gain a new sense, build a new common sense, morality, or ethics on this basis, or move toward institutional reform. For this reason, a special fabricated object that can force ordinary people to be aware of site landing is necessary. There, people like Pollock and master crafters utilize their bodies to collaborate with the environment and realize landing sites procedurally.

However, we must not forget that people do not move as they like upon finding landing sites. They are semi-forced to reshape their physical sensations owing to environmental loads. In addition, they must follow various verbal instructions from Arakawa + Gins: "Enjoy (with the intention of recreating your senses) rather than being afraid to lose balance," "If you feel like you're inside and out of balance, shout out your name. It could be someone else's name," "Try to find a clear resemblance between yourself and the house. If you cannot, think of this house as your twin and walk," and "If something unexpected happens, stop there and take a better posture (to think it through) for about 20 s." These are examples from the "Site of Reversible Destiny Yoro." People must trust Arakawa + Gins and take the risk of entrusting the whole body to the environment and verbal instructions at your own will.

\subsection{Transforming Humanity as a Whole}

Regarding the second point, Arakawa + Gins stated:

"What then is preventing us from inventing ourselves further? The answer comes quickly: the species [human beings] has not yet learned how to have its members pull together to work communally at the same time they constitute to form themselves as separate individuals. The species is in need of a common purpose, fueled by a sharp sense of a shared plight, and a concerted communal effort to address this purpose. And this is so, despite the fact that every individual has been formed communally, and that therefore all actions have communal echoes and repercussions (this is easily proven). For members of our species to arrive at having a great many more than the paltry sum of possibilities that is usually their due, there needs to be a communal devising, selecting, and combining of techniques that will strengthen organisms-persons and help them to regenerate themselves; results need to be pooled and compared" [4] (p. xxi).

Engaging many people in one and the same fabricated object means forming an individual perspective and working as a community at the same time, thereby transforming humanity as a whole while each individual makes their own site landing. This is what Arakawa + Gins' work approached. Why did they think about this? The reason seems to be related to their philosophy of stopping death-based upon the idea of reversing the destiny of human beings as mortal.

Arakawa + Gins also stated:

"Without doubt, the human race has hideously acquiesced in regard to its own abysmal fate. Underlying all cultures, in East and West alike, is this assumption or attitudinal stance; we- each and every one of us-must die, no doubt about it, for all those who lived before us died. Everyone wants to insist on this. A bunch of defeatists" [4] (p. xiv).

"The defeatists are everywhere. Within the life sciences, they try to cure the human body or figure it out, such as they find it to be, never attempting to 
reconfigure it alto-gether, never thinking to reorder the body radically so that it might elude mortality" [4]. (p. xvii).

"An architecturally guided and sustained organism-person should then be able to reverse that destiny [mortality] known to have been the lot of billions of other members of her species; when it becomes possible for an organism-person simply to go on in-definitely, a reversible destiny shall have been achieved" [4]. (p. xx).

What does it mean to not die? After all, are their remarks only esoteric? They do not have to be considered as such. According to Shunkichi Baba, the reversal of destiny by Arakawa + Gins occurs in the following two stages: first, the infinite creativity of life or of human beings is externalized as a tangible object (architectural body). Then, a third-party body experiences the tangible object. In this way, life or creativity is transcribed into the body of a third party. As long as this is passed on from generation to generation, that life will not end. This is the reverse of the human destiny of being mortal [1] (pp. 135-136).

Baba says that "life or creativity is transcribed into the body of a third party" through landing sites. However, given what has been said so far, it is not necessary to take this transcription literally. Each person has a slightly different body and lands sites in a slightly different way. It is important to note that a very large number of people experience this change simultaneously and continuously. To use Danto's words again, through such an individual but communal experience, Arakawa + Gins tried to "falsify [ ... ] the 'All men are mortal' premise of a famous syllogism." [2] (p. 268)

\section{How Can We Inherit the Idea of Landing Sites and Hand It Over to the Next Generation? The Current Problems of Landing Sites}

There are, however, some problems with Arakawa + Gins' landing sites. Here, I address two problems related to landing sites as material constructions. However, the reason I point out the problems with landing sites here is not to diminish their value. Instead, I believe that now is the time to seriously consider how to pass the possibilities that Arakawa + Gins showed nearly 30 years ago on to the next generation.

First, the intention of Arakawa + Gins was not completely realized, especially in large-scale manufactured objects such as "Site of Reversible Destiny Yoro." Artist and critic Kenjiro Okazaki stated in an interview:

"I think that it is in the "Ryoanji Temple in Nagi" and the "Site of Reversible Destiny of Yoro" that the problem is specifically exposed. In other words, when the scale becomes large, a complicated function that cannot be recovered by such a function comes out even if one asks why the thickness of the wall is like this. Another function is responsible for determining the thickness of the wall. People who are watching will also feel this. Even when I entered the maze, I felt that the walls were thick before I felt the direction. What I felt was the texture of the wall's surface sprayed with lysine. If it is thick, you never feel the direction of the wall. I did not feel it in the maze. Arakawa + Gins should have done it to confuse a function, but instead of arriving at that function, people end up with another function" [8] (p. 365, translation from Japanese to English by the author).

The phrase "such a function" seems to refer to the conditions that must be met when transferring the body movements that Arakawa envisioned to the structure of the artificial object. However, in the case of a large-scale fabricated object, due to budget constraints, the intervention of the government and contractors, etc., it was not possible to produce all the details as Arakawa + Gins intended. Therefore, the experiencer reacted to something completely different from the intention of Arakawa + Gins (for example, "the thickness of the wall" or "the texture of the wall's surface sprayed with lysine"), and the experiencer's site landing was hindered-namely, it will end up in another function without reaching the intended function.

There are further complications related to this issue. It is very difficult to update the contents once it is installed, and, in addition, because it is an artificial object, deteriora- 
tion over time is unavoidable, which causes it to move further away from the original intention [9].

These points are related to landing sites as material constructions. They may not seem to be an essential issue because landing sites can only be achieved through collaboration between persons and the environment. However, at least the second point has a negative effect on landing sites. There are some parts that are banned from use in the "Site of Reversible Destiny of Yoro" because they have become old and dangerous [9] (pp. 142143; the photos on page 143 show a building with some missing components that is left un-repaired and its damaged parts are being repaired with vinyl tape in a very unsightly way). The ban might deprive the landing sites of the power to cause people to transform. Therefore, this cannot be overlooked.

Even if these problems are solved by investing significantly in maintenance, the following problems remain: if a person lives in a place far from the "Site of Reversible Destiny of Yoro" and can only go there once in a lifetime, will their destiny be reversed in just one experience? Is social reformation impossible unless we can provide more sustainable experiences to more people? In fact, a report from one who has experienced it addresses this as follows: "The sense of balance that I have cultivated in reality for 30 years does not collapse in half a day at Arakawa World. If I fall down and see it once, I may have 'tasted' something" [10] (p. 243). Of course, we can stay in "Reverse Destiny Lofts Mitaka" for more than three nights, but even so, the possibility for people working outside the Tokyo area to stay there-unless full telework is allowed during their stay-will be very low.

Moreover, how can Arakawa + Gins actually direct those who have experienced new sensations through landing sites to change society? What should we do after experiencing the landing sites at Yoro? Are many people satisfied only with experiencing "Site of Reversible Destiny of Yoro"?

If these problems cannot be solved, the simultaneous realization of individual body formation and communality required by landing sites will continue to be hindered.

In this way, tactileological research conducted by Yasuhiro Suzuki in recent years is extremely important. As we will see in the next chapter, tactileological research attempts to provide more sustainable landing sites without sharing a specific place, based on the tactile recording/creating medium and tactile score, and to direct people to reform the social system through collaboration with an audio-visually disabled person, that is, a tactile superior.

\section{Tactileological Research and Its Inheritance of Landing Sites}

However, tactileological research is not an art, it is first a scientific inquiry that may later be applied to art. Nor did it begin with the goal of solving landing site problems. However, it inherits the idea of landing sites. Of course, I am not saying that tactileological massages and landing sites at, for example, Yoro have the same quality of experience. Even if they are the same, they cannot be proven in any experiment. Even the same Yoro experience could vary depending on the individual who experiences it. So, for what reason do I claim that tactileology inherits the idea of landing sites? This becomes clear by comparing the characteristics of tactileology with those of landing sites.

The tactileological research by Suzuki et al. included the following [11].

- $\quad$ Tactile Score ${ }^{\circledR}$, Shoku-fuTM;

- $\quad$ Tactile massage using T-bit;

- T-bit conversion of the sensory world of tactile superiors and conversion to the vibrotactile.

In the following, from Section 5.1 to Section 5.3, I introduce each piece of research one by one and discuss how each inherits the characteristics of the idea of landing sites. Finally, in Section 5.4, I make clear that tactileology inherits the ideas of "architectural body" and "architectural procedures," closely related to the idea of landing sites.

Now I begin with the tactile score. 


\subsection{Tactile Score}

First, the tactile score [12] was originally developed as a notation for facial massage.

"To investigate massages, we have developed a notation for describing massages, the Tactile Score ${ }^{\circledR}$ [13]; we borrow a notation of music score. We have found that a massage is composed of three main basic elements; they are pressure, contact area, and rhythm; hence by describing these three elements, we are able to describe tactile sense of massage precisely" [14] (p. 18).

First, massage is typically process-based, procedural, and corporeal. It is realized only through collaboration between massagers and massages each time. The tactile score has a great advantage in that, by describing these three elements (in other words, the magnitude and length of force and strength) according to the rules, it is possible to record a massage that disappears when you touch and release it. Then, if it becomes possible to describe the massage according to the rule, the recorded massage can be read out by applying the same rule and reproduced. Moreover, because the tactile score is portable, the massage has been given unprecedented mobility. The massage recorded by each tactile score is individual; however, by copying and distributing it, it is possible to produce a tactile experience that can be shared by many people.

Massage performed using this tactile score is considered to be a type of landing site because it incorporates the three landing sites we noted above. Massage is a dimensional site that is created and landed by combining the direct perception of touching others (perceptual landing site) and indirect perception through the tactile score (imagining landing site). Furthermore, it seems to realize the ideal of the landing site because tactile massage is both individual and communal body formation.

However, even if the massage is performed by referring to the tactile score, as long as it is performed manually, it may make a difference depending on the person who is massaging. As pointed out in the previous section, there may be suspicion that the experiencer may react in a way that is not what the designer intended. This point is further confirmed through "Tactile massage using T-bit" by Suzuki et al. (2019) [11].

\subsection{Tactile Massage Using T-Bit}

The tactile score can be used not only for tactile stimuli, but also for recording, reproducing, and creating general emotional information. Suzuki et al. found that they could describe all the data, even that of sound or character text, by tactile score if they paid attention to the "change in the magnitude and length of force and strength" inherent in the data. Suzuki et al. called this the tactile score, whereby emotional information (not only tactile stimuli) was described as "T-bit" [11] (p. 398).

Using this T-bit, for example, the conversion from a novel via T-bit to massage, or from a piece of music via T-bit to massage, is possible. Furthermore, by converting the change in the strength of the T-bit into the magnitude of the amplitude of the vibrating tactile sensation (vibro-tactile), any T-bit can yield a vibrotactile output. This has made it possible to convert the massage into T-bit and output it as a vibro-tactile, and, as a result, "it became possible to perform the same quality massage to a large number of respondents at the same time" [11] (p. 399). In addition, this vibro-tactile system can be distributed via the internet, similar to music software.

Furthermore, a device that reproduces this vibro-tactile sensation has been developed, named the Vibrotactile-Music Player (VMP). By using it, you can literally experience the same quality of vibro-tactile sensation, regardless of whether you can obtain an internet environment and playback equipment (same as above). The vibro-tactile experience is just an individual experience, but, at the same time, it is also a community experience. It can be said that these doubts have been dispelled.

\subsection{T-Bit Conversion of the Sensory World of Tactile Superiors and Conversion to Vibro-Tactile}

However, people may also express the following suspicions. Many people remembered Arakawa + Gins in 2020 because when people faced the restrictions on bodily contact 
under the coronavirus infection, they sought a breakthrough in the new bodily experience that Arakawa + Gins sought. This was not only because they wanted a substitute for tactile stimuli as before. Can tactileological research provide new bodily sensations that can lead to ethical and institutional changes?

This suspicion can be answered by recalling the existence of a tactile superior. Here, the tactile superior refers to a person who can systematize the world only through the sense of touch, such as Mr. Norimasa Kawasora, who has visual and hearing disabilities [11] (p. 401). The expression that Mr. Kawasora converted his sensory world into T-bit using tactile score and then into the vibro-tactile is completely different from the expression created by an audiovisual superior [15]. Of course, anyone can experience the vibro-tactile sensation by using the above-mentioned VMP. The experience is powerful enough to make us realize the narrowness of the current social systems created based on the sensory world of audiovisual superiors and to consider the need for social change. In fact, Suzuki et al. are engaged in social activities that change society, such as creating employment for people with disabilities through tactileological research. Such research has already exceeded the level of substitution and reproduction of tactile stimuli.

Some might argue that taking a risk on their own initiative and thus gaining a new bodily experience at the "Site of Reversible Destiny Yoro" is completely different from passively experiencing a massage. However, this is not true for at least two reasons. First, massage is also something that you will never receive unless you are willing to seek it out. You must trust the person who is massaging and take the risk of entrusting the whole body to that person at your own will, just as you must trust Arakawa + Gins and faithfully follow their instructions at the "Site of Reversible Destiny Yoro". Second, persons and massages or vibro-tactile sensations always collaborate with each other. The most obvious example would be dance. When dancers, including hearing-disabled dancers, are dancing to vibro-tactile sensations generated by T-bit of music, they obviously move their bodies with them [11] (p. 399). Finer collaboration is indicated by measuring brain activation as well as Amylase concentration [14] (pp. 27-33).

\subsection{How Tactileology Inherits Two Architectural Procedures}

Thus far, I have confirmed what tactileology has inherited from the idea of landing sites. Finally, I would like to consider this inheritance from the perspective of "architectural body." Arakawa + Gins describe the architectural body in various ways. The following is an example.

"All that emanates from a person as she projects and reads an architectural surround forms an architectural body that moves with her, changing form depending on the positions she assumes" [4] (pp. 66-67).

In this paper, this has been explained several times in terms of the collaboration between the persons and the environment. Therefore, it is easy to understand the following sentence.

“Only procedures and proceduralism, not mere form or formalism, can redistribute and reconfigure the architectural body of an organism that persons" [4] (p. 74).

Arakawa + Gins calls such a procedure related to an architectural body an "architectural procedure".

"Not a fixed set of called-for actions, an architectural procedure is a spatiotemporal collaboration between a moving body and a tactically posed surround" [4] (p. 73).

Then, Arakawa + Gins introduce two architectural procedures. One is the "disperseto-contrast procedure," and the other is the "tentativeness-cradling procedure". These two procedures are also explained as follows:

"Tactically posed surrounds that contrast one segment of world with another prompt sequences of actions that add up to an observational-heuristic procedure 
we have named the disperse-to-contrast procedure. This procedure orchestrates dispersions of landing sites under contrastive conditions that cause them to stand out so as to be more easily assessed" [4] (pp. 74-75, Italics by the original author).

“Tactically posed surrounds set up to generate or maintain a person's tentativeness in her forming of the world prompt sequences of actions that add up to a reconfigurative or transformational procedure we name the tentativenesscradling procedure. Someone living within a tactically posed surround that houses the tentativeness-cradling procedure will be forever getting her bearings only tentatively" [4] (p. 76, Italics by the original author).

\subsubsection{Disperse-to-Contrast Procedure}

First, I will confirm how the former is inherited in tactileology. Arakawa + Gins describe how environments initiate this procedure as follows.

"It comes down simply to this-sets of contrastive surfaces and volumes needed to be put in place." "Architectural surrounds thus paired can be constructed either as identical twins (that they are positioned differently of course precludes identicalness) or as similar volumes containing slight but significant differences. When differences within and between tactically posed surrounds are being compared, the disperse-to-contrast procedure is in progress" [4] (p. 75).

In the "Site of Reversible Destiny Yoro," such a structure is found in, for example, the Critical Resemblance House and the Elliptical Field. In the Critical Resemblance House, various elements are repeatedly placed with subtle differences, and each small building dispersed over the Elliptical Field is a replica of a piece of the Critical Resemblance House. Such a contrast between one segment and another "prompt sequences of actions that add up to an observational-heuristic procedure," that is, the "disperse-to-contrast procedure."

In the case of tactileology, a collaboration between a person and an architectural surround which forms an architectural body would be replaced by a collaboration between a person and a massage or a person and a vibro-tactile sensation. The collaboration between the two continuously reconfigures an architectural body in a tactile experience.

Then, can we think that massages and vibro-tactile sensations as the environment prompt the disperse-to-contrast procedure so as to collaborate with a person who experiences them? In the case of musical works, it is quite normal for the same phrase or sound to appear in different contexts or for one basic motif to be repeated with subtle differences in its temporal development. Massage, like music, develops over time. Therefore, massages as an environment also initiate the disperse-to-contrast procedure.

Furthermore, regarding massages, a massage by a tactile superior should be considered as "containing slight but significant differences" from a massage by an audiovisual superior. Through contrasting a massage by a tactile superior with another by an audiovisual superior, we heuristically act with others, gain new bodily sensations, and move to social reformation. In this sense, tactileology inherits the disperse-to-contrast procedure for the architectural body.

\subsubsection{Tentativeness-Cradling Procedure}

Regarding the second procedure, Arakawa + Gins explains as follows.

"The tentativeness-cradling procedure cannot help but get underway here. This architectural procedure also blossoms forth within a house of our design that has twenty entrances. Someone having an entrance available to her wherever she turns, with every path she comes upon likely to lead to a welcome mat, will, whether she feels hesitant or not as to where to begin, be continually in the start-again mode, reveling in that tentativeness which the moment just prior to entry brings" [4] (pp. 76-77).

In the "Site of Reversible Destiny Yoro", such a structure is found also in the Critical Resemblance House. However, a massage cannot present as many as twenty entrances 
simultaneously because it unfolds in time. Then, what in tactileology gives us multiple entrances and continuously keep us in the start-again mode? The temporal character of the massage mentioned above is also related to the tentativeness-cradling procedure. Even if a massage starts with the same massage method as before, there are numerous combinations of subsequent massages. Even though a tactile score can record massages, there is no way to experience them other than from the beginning each time. It is always tentative, and we will be continually kept in the start-again mode. In this sense, massages and vibro-tactile sensations prompt the tentativeness-cradling procedure. Tactileology also inherits the idea of the architectural body.

\section{Conclusions}

This paper discussed the following to clarify that the idea of "landing sites" by Arakawa + Gins has been inherited by tactileological research in a different way. First, I confirmed that Arakawa + Gin's "landing sites," which are closely related to the body, are created by combining the perceptual landing sites and the imaging landing sites. In addition, I also emphasized Arakawa + Gins' hope that people would build new common sense, morals, and ethics and move toward institutional reform based on the new sensations gained through the experiences of such landing sites. To realize their hope, the personal experience of landing sites must also be a communal experience that can be shared. However, the current situation of material constructions produced by Arakawa + Gins limits the realization and maintenance of landing sites.

Tactile massage, which has been promoted by tactileological research, using perception and images similar to landing sites, simultaneously realizes the personal experience of tactile stimulus and its communal sharing. In addition, it makes the tactile superior's sensory experience via tactile score and T-bit accessible to everyone. In this way, it gives people a new sensory experience by which tactileology begins to direct them toward the construction of new social institutions. From the above, it is considered that tactileological research has inherited Arakawa + Gins' idea of "landing sites" and still gives us opportunities to reconsider the will of Arakawa + Gins in the modern era.

Funding: This research was funded by JSPS KAKENHI, grant number $19 \mathrm{H} 00517$.

Conflicts of Interest: The author declares no conflict of interest.

\section{References}

1. Baba, S. Imi No Kanata e: Arakawa Shusaku ni Yorisotte [Beyond Meaning: Standing by Shusaku Arakawa]; Shoshin Yamada: Tokyo, Japan, 2016.

2. Danto, A.C. The Madonna of the Future: Essays in a Pluralistic Art World; Farrar, Straus, and Giroux: New York, NY, USA, 2000.

3. Shusaku Arakawa + Madlin Gins Tokyo Office Starts Newsletter. Available online: https://bijutsutecho.com/magazine/news/ headline/21671 (accessed on 12 July 2021).

4. Gins, M.; Arakawa, S. Architectural Body; The University of Alabama Press: Tuscaloosa, AL, USA, 2002.

5. Kawamoto, H. Soryoku Sen II: Arakawa+Gins no sono Muko [A Total War II: Beyond Arakawa+Gins]. In Sinunowa Horitsu Ihan desu: Shi ni Kosuru Kenchiku, 21 Seiki eno Genryu [Making Dying Illegal, Architecture Against Death: Original to the 21st Century]; Gins, M., Arakawa., S., Eds.; Shunju Sha: Tokyo, Japan, 2007; pp. 357-386.

6. Gins, M.H. Arakawa: From Diagram to Model. In Kaiga ni Tsuite no Kotoba to Imeji: Arakawa Shusaku Ten [Words and Images on Paintings: The Exhibition of Shusaku Arakawa]; Seibu Museum: Tokyo, Japan, 1979.

7. Reversible Destiny Talk. Available online: http://www.architectural-body.com/?p=6723 (accessed on 14 July 2021).

8. Okazaki, K. Zero no Polemic [Polemic of Zero]. In Gendai Siso: So-tokushu Arakawa Shusaku + Madelin Gins [Review of the Present-day's Thought: Featuring Shusaku Arakawa and Madelin Gins]; Seido Sha: Tokyo, Japan, 1996; Volume 24, pp. 360-366.

9. Hirayoshi, Y. Bijutsu no Hozon, Kenchiku no Hozon: Arakawa Shusaku no Kenchiku-teki Sakuhin kara Kangaeru [Conser-vation of Artworks, Conservation of Architecture: Thinking from Shusaku Arakawa's Architectural Works]. In Gendai Bi-Jutsu No Hozon to Shufuku: Sono Rinen, Hoho, Joho No Nettowaku Kochiku No Tameni [Conservation and Restoration of Contemporary Artworks: For Principles, Methods, and the Construction of Information Network]; Okada, A., Ed.; Final Report for the Grant Aid KAKENHI No. 15H01871; Kyoto University Okada Laboratory: Kyoto, Japan, 2020; pp. 135-146.

10. Nagao, C. Yoro no Aomi wo ARAKAWA de Taberu to [When you eat the blueness of Yoro with ARAKAWA ... ]. In Gendai Siso: So-Tokushu Arakawa Shusaku + Madelin Gins [Review of the Present-day's Thought: Featuring Shusaku Arakawa and Madelin Gins]; Seido Sha: Tokyo, Japan, 1996; Volume 24, pp. 231-246. 
11. Suzuki, Y. Shokufu wo Mochiita Kansei no IoT-ka to Kansei Infomotion eno Oyo [IoT of Sensibility by Using Tactile Score and Its Application for Sensibility Information]. In Nihon AME Gakkai-shi [Journal of the Japanese Society of Applied Electromagnetics and Mechanics]; Nihon AME Gakkai: Tokyo, Japan, 2019; Volume 27, pp. 396-401.

12. Tactile Score. Available online: https://www.sensory-communication.info (accessed on 14 July 2021).

13. Suzuki, Y.; Suzuki, R. Tactile Score: A Knowledge Media for Tactile Sense; Springer: Tokyo, Japan, 2014.

14. Suzuki, Y. Computational Aesthetics. In Computational Aesthetics; Suzuki, Y., Ed.; Springer: Tokyo, Japan, 2019; pp. 1-36. [CrossRef]

15. Create a Mechanism for Social Participation and Independence of Persons with Disabilities and the Elderly. Available online: https: / / www.norimasa.net/ (accessed on 14 July 2021). 